\title{
Polycystic Ovary Syndrome: Explaining the Gynecological Aspects and Treatment Options to Patients
}

\author{
Robert L. Reid* \\ Professor of Obstetrics and Gynaecology, Chair, Division of Reproductive Endocrinology and Infertility, Queen's University, \\ Kingston Ontario, Canada
}

Received: July 15, 2015; Accepted: August 04, 2015; Published: October 31, 2015

*Corresponding author: Robert L Reid, Professor of Obstetrics and Gynaecology, Chair, Division of Reproductive Endocrinology and Infertility, Queen's University, Kingston Ontario, Canada, K7L 2V7, E-mail: Robert.reid@queensu.ca

\begin{abstract}
Polycystic Ovary Syndrome (PCOS) is one of the most prevalent conditions leading to reproductive and metabolic health concerns for women. The apparently disparate consequences of this disorder ranging from menstrual dysfunction to hirsutism, infertility and endometrial cancer create a confusing picture for clinicians and often result in an inadequate explanation for affected women. This article will provide a simple construct for PCOS which will allow health care providers to inform and motivate women in a way that optimizes treatment for these conditions.
\end{abstract}

Keywords: Polycystic ovary syndrome; Patient education; Treatment

\section{Background}

Polycystic ovary syndrome is a term that encompasses a variety of phenotypes and has been associated with both reproductive (oligomenorrhea, acne, hirsutism, androgenic alopecia, infertility, endometrial hyperplasia and malignancy) and metabolic (dyslipidemia, diabetes, Non-Alcoholic Fatty Liver (NAFLD), Non alcoholic Steatosis Hepatitis (NASH) and cardiovascular disease) consequences that can impact the health and quality of life of women from puberty until death [1-6].

Explaining the etiology and the proposed interventions to affected women in a clear but simple fashion can provide confidence in the therapeutic recommendations and enhance compliance -both essential for achieving treatment goals.

This article will provide a brief summary of the latest information about PCOS and then explain how this information can be woven into a clear and simple explanation for patients.

Several different definitions for PCOS have emerged from international consensus conferences. In 1990, the National Institutes of Child Health and Human Development in the USA concluded that essential features for the diagnosis were hyperandrogenism and chronic an ovulation [7]. In 2003, the European Society for Human Reproduction and Embryology (ESHRE) and the American Society for Reproductive Medicine
(ASRM) met in Rotterdam and reached the conclusion that a third feature was relevant the presence of polycystic ovaries on ultrasound $[8,9]$.

At this conference, there was acceptance of the fact that there were different phenotypes and accordingly any two of the three identified criteria were considered sufficient to establish the diagnosis. This, unfortunately, has led to multiple phenotypes only some of which are at risk for metabolic disease [10].

More recently, in December 2012, the National Institutes of Health Office for Disease Prevention convened the first Evidencebased Methodology Workshop on Polycystic Ovary Syndrome [11]. These discussions led participants to suggest modifications to the name polycystic ovary syndrome that would better define and recognize the reproductive features and the longterm metabolic risks associated with the condition. Thus far no consensus on a name change has been reached [12,13].

PCOS starts to manifest at puberty and research suggests that it is not diagnosed in a timely fashion in the majority of cases [14]. A history consistent with infrequent menstruation in conjunction with the gradual onset of hirsutism is highly suggestive of PCOS and will identify women at risk for ongoing reproductive dysfunction and longer term metabolic problems. Ovarian ultrasound is not required to establish the diagnosis however this test may later be useful to determine ovarian reserve and risk for hyperstimulation for women seeking assisted reproductive therapies employing injectable gonadotropins.

\section{The Basics of the Normal Menstrual Cycle}

To understand the essentials in explaining PCOS the practitioner should be aware of the sequence of hormonal changes that define and regulate the normal reproductive cycle. Figures 1, 4 and 6 assist in understanding the pathophysiology but are probably too advanced for most patients. On the other hand Figure 2 Panels A, B, C and D as well as Figures 3 and 5 link the symptoms and signs with treatment options and afford a relatively simple way to explain PCOS to patients in the office. 


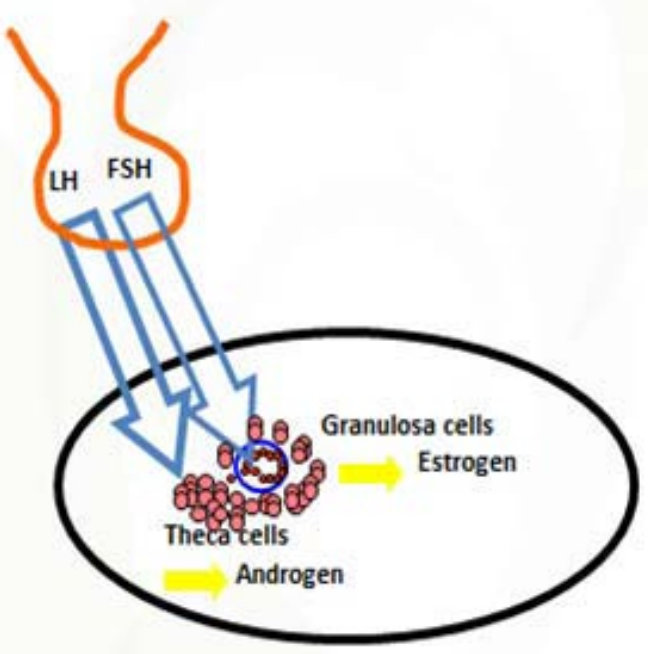

Figure 1: The two cell hypothesis. FSH stimulates multiplication of granulose cells within the follicle and augments the aromatase enzyme. LH drives ovarian theca cell androgen production. Androgens diffuse into the follicle where they are converted by aromatase to estrogen. Estrogen is released back into circulation.

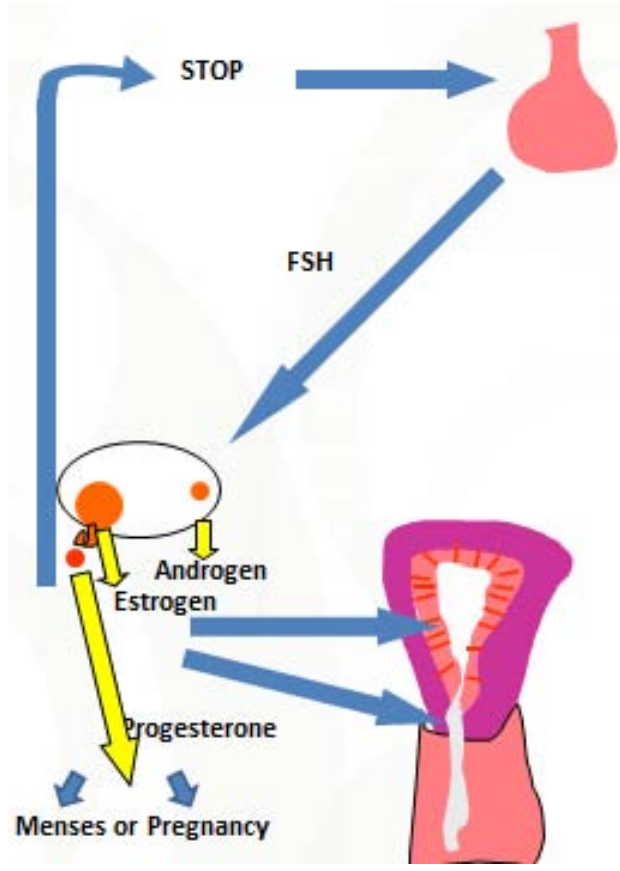

Figure 2: Panel A. A simple drawing is used to explain PCOS to affected women and their partners. The drawing is started by depicting normal events of the menstrual cycle on one side of a sheet of blank paper.

Follicle Stimulating Hormone (FSH) levels in circulation rise as pituitary output increases in response to the declining levels of oestrogen and progesterone from the dying corpus luteum of the previous cycle. The amount of FSH is a critical determinant of the number of follicles and their rate of development in the cycle at hand. FSH acting on the granulosa cells that line the inside of the follicle causes granulosa cells to multiply and develop the enzymatic capability to turn androgens into estrogen-a process called aromatization. Luteinizing Hormone (LH) from the pituitary acts primarily on the other cell type in the ovary-the theca cells. These larger cuboidal cells, or interstitial cells as they are also known, lie just outside the basement membrane of the developing follicle and produce androgens which diffuse through the basement membrane into the follicle to act as the substrate for estrogen production. This is known as the two cell hypothesis: LH acts on the theca cells to cause them to produce androgen and FSH acts on granulosa cells to convert this androgen to estrogen. The estrogen then diffuses back into circulation.

Estrogen from the mature follicle returns to the circulation and has feedback effects on the hypothalamus and pituitary

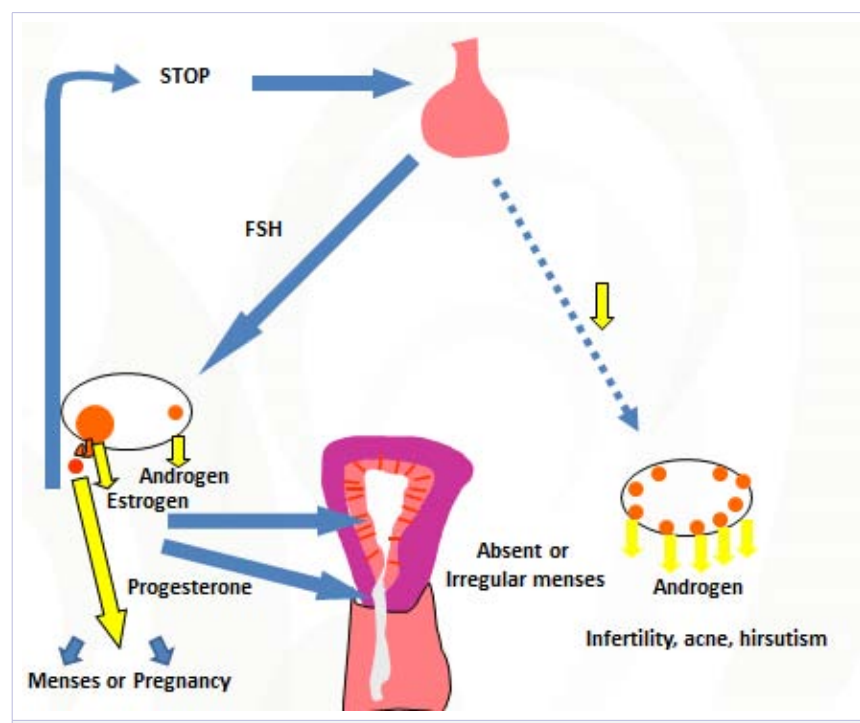

Figure 2: Panel B. In the centre of the drawing the effect of diminished FSH release on ovarian follicular development is depicted.

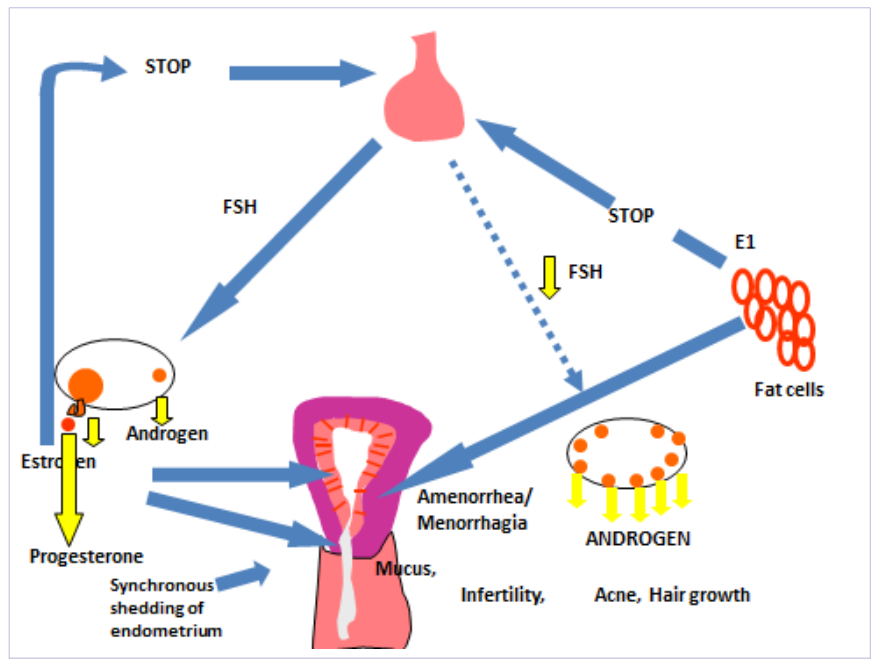

Figure 2: Panel C. Fat cells are now depicted to explain that for obese PCOS patients peripheral production of estrogen can cause endometrial overgrowth, cervical mucus excess and negative feedback on FSH release. 


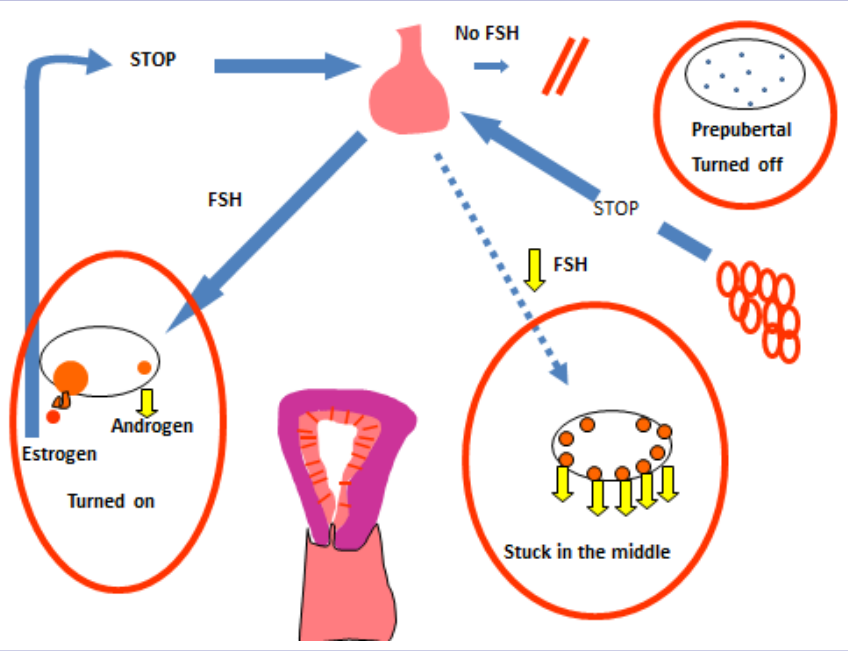

Figure 2: Panel D. This completed drawing demonstrates that women with PCOS are neither fully "turned on" nor fully "turned off". Depending on the desire for pregnancy one of these options becomes the target for treatment.

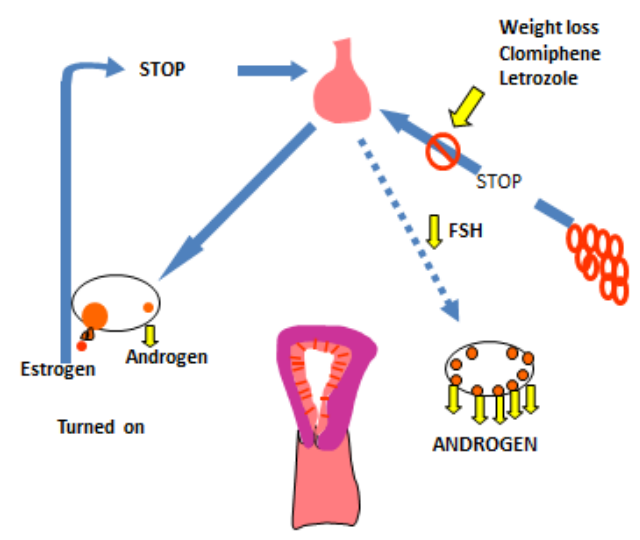

Figure 3: Shows therapeutic interventions (that can be superimposed on the original drawing) to explain how blockade of the negative estrogen feedback from fat cells can return the reproductive cycle to the "turned on" status.

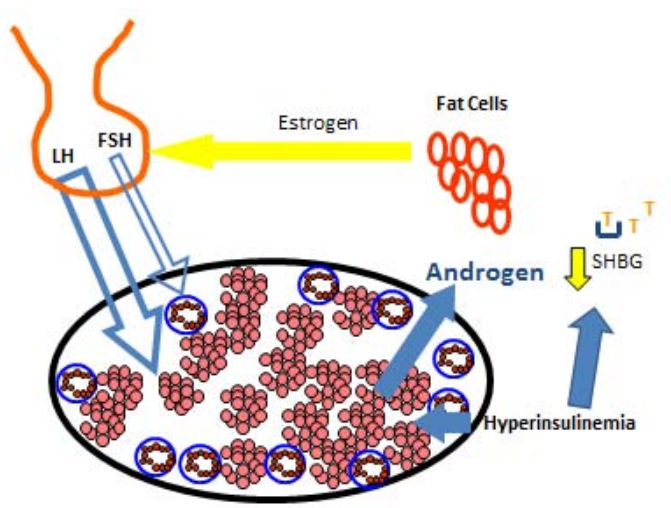

Figure 4: Hyperinsulinemia augments androgen action by increasing ovarian theca cell androgen production and by decreasing Sex Hormone Binding Globulin (SHBG).

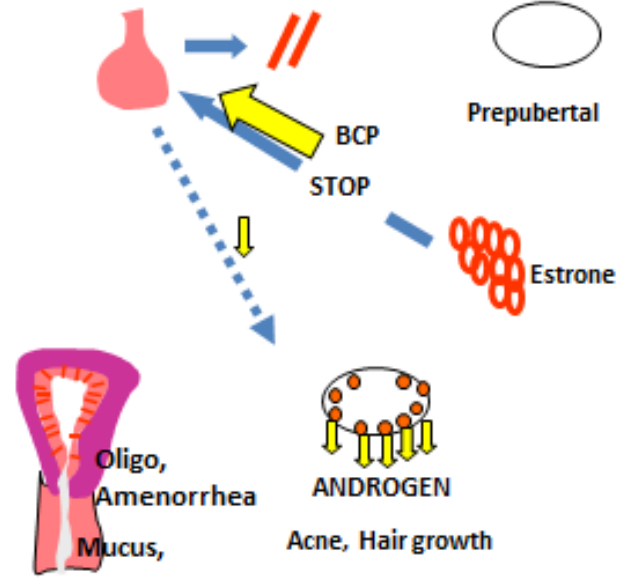

Figure 5: Combined hormonal contraception augments the negative feedback to hypothalamus and pituitary thus suppressing FSH release and returning the ovary to the inactive prepubertal state.

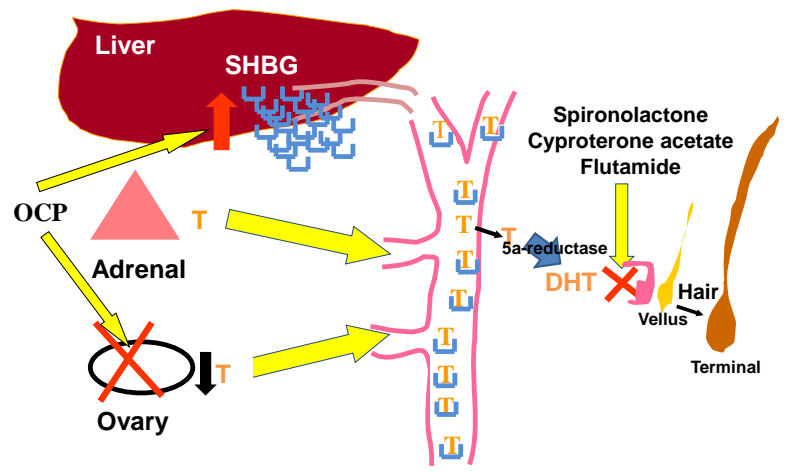

Figure 6: The synergistic action of combined hormonal contraception and the sites of action of other antiandrogens used to treat hirsutism in PCOS.

which diminish FSH release and augment LH release in a lead up to the mid cycle LH surge. This mid-cycle LH surge results in the final maturation of the oocyte and ovulation approximately 30-36 hours after the initiation of the surge. After ovulation, the hormone production from the follicle (now called a corpus luteum) changes such that progesterone secretion dominates over the next 10-12 days. Progesterone is essential in preparing the endometrium for implantation. Progesterone exposure also causes formation of cytosolic granules containing prostaglandins within the endometrium. If implantation does not occur and there is no embryonic HCG to rescue the corpus luteum progesterone levels plummet. This, in turn, triggers the simultaneous disruption of the cytosolic vacuoles, release of prostaglandins, and constriction of endometrial vessels all of which result in a time-limited or synchronous shedding of the endometriummenstruation. 


\section{Explaining PCOS}

The explanation of PCOS to the patient begins with a very simplified version of what is to be expected in a normal cycle as outlined in Figure 2, Panels A, B, C and D. Treatment options can be clarified with the addition of the therapeutic choices as shown in Figure 3 and 5.

A step-by-step drawing as the explanation unfolds allows the patient to understand the essentials of normal reproductive cycle and then to appreciate the differences between normal and PCOS.

First it is helpful to explain that the pituitary is the "master gland" of the body and that it sends a message, "FSH", to the ovary each month to initiate development of one of the many eggs held within. As the egg develops it does so in a small fluid filled sac called a follicle. Initially the follicle produces mostly "male-like hormones" but as it grows it develops the capability to convert these into the female hormone estrogen. Estrogen has many different effects in the body and three important effects in preparing for pregnancy.

o Estrogen at the cervix creates watery cervical mucus that allows sperm to transit up into the reproductive tract from the vagina.

o Estrogen acts like fertilizer on the lining of the uterus and causes it to grow in preparation for implantation and

o Estrogen courses back through circulation to the brain to let the brain know that there is one mature egg ready to burst and that it is time to stop sending FSH to avoid multiple pregnancies.

When the egg bursts one of two outcomes results two weeks later: either she will get a menstrual period or she will not (due to pregnancy). This overview explains in lay terms the normal reproductive cycle.

Beside this the pathophysiology of PCOS is depicted (Panel B). A dotted line from pituitary to ovary indicates that in PCOS there is diminished release of FSH. This inadequate amount of FSH starts the development of an ovarian follicle but does not support its growth to full maturity so its growth stalls. This is repeated month after month until the surface of the ovary becomes lined by small partially developed follicles. As discussed previously each small follicle is producing 'male-like hormones' and additively the result are higher circulating levels of androgens (which result in acne and hair growth). Because the eggs do not mature and ovulate the two final outcomes of the reproductive cycle (regular menses or pregnancy) do not occur...resulting in irregular or absent menstrual periods and infertility.

At this point it is useful to offer an explanation of why this diminished FSH has occurred. Small circles drawn to the side of the diagram (Figure 2 Panel C) represent body fat and can be used to explain that (for obese women with PCOS) the fat cells are the culprit. Each fat cell is able to make a small amount of estrogen and additively as body fat increases the amount of estrogen in circulation increases. This estrogen has the same three effects described for the normal cycle: continuous exposure to estrogen results in production of clear watery mucus (many women with PCOS admit the need for a "light days" pad due to watery discharge), the estrogen stimulates growth of the endometrial lining -resulting in episodes of heavy irregular bleeding and the potential, if prolonged, endometrial hyperplasia or malignancy. Most importantly the estrogen feeds back on the pituitary to suppress the release of FSH. (Figure 2 Panel C)

One third of women with PCOS are of normal body weight and the diagram can be modified to indicate an uncertain source of estrogen feedback (other than fat cells) such as the adrenal.

The addition of one further drawing - an image of an ovary with eggs in it but no follicular development (Figure 2 Panel D) can be used to show how the prepubertal ovary has eggs but no follicles because reproductive immaturity results in negligible release of FSH into circulation.

\section{Counselling about Treatment Options}

This background sets the stage for an explanation about treatments. Treatment direction will be defined by the patient's desire for pregnancy or not so this should first be ascertained.

\section{If pregnancy is desired the goal is to shift to the "turned on" mode}

Lifestyle modification: As far back as 1874 G H Napheys wrote "There are well authenticated cases of women who were stout and barren in opulence becoming thin and prolific in poverty" $[15,16]$. Over a century later research on obesity and reproduction confirmed that obesity correlated directly with poor reproductive outcomes [17] and that weight loss would correct gonadotropin and sex steroid abnormalities and restore fertility in women with PCOS [18-20].

Diet and exercise should be recommended for all obese women with PCOS [21,22]. For many obese women weight loss has been a lifelong challenge and it is important to set a small realistic goal in order to give them hope that they can succeed. Often a negotiation to give them assistance with an oral fertility drug if they can lose $10-20 \mathrm{~kg}$ is sufficient motivation to effect change. For obese PCOS patients weight loss of $5-10 \%$ is often enough to reinitiate ovulatory cycles. Bariatric surgery will also correct PCOS in many circumstances [23]. From the drawing and the explanation women can readily understand that the body fat cells are primarily responsible for their condition and for many this creates motivation to lose weight. For PCOS patients of normal weight there is no benefit from weight loss.

Metformin: Whether all women with PCOS will benefit from this insulin sensitizing agent is controversial. Insulin resistance is difficult to establish in clinical practice and many surrogate tests are available, although their value in the clinical setting is uncertain $[24,25]$. Some experts have argued that women with PCOS should only be treated if there is confirmed insulin resistance [26]. However, others report beneficial effects in most women with PCOS $[27,28]$. For women with PCOS and menstrual irregularity, or obesity and clinical features of insulin resistance (acanthosis nigricans) it is reasonable to initiate treatment with 
metformin during an initial three month period during which the success with weight loss is evaluated.

Metformin therapy (introduced slowly in weekly increments of $500 \mathrm{mg}$ to a maximum of $1000 \mathrm{mg}$ bid) should be considered at this visit and the patient warned about possible gastrointestinal side effects. Available data indicate a limited benefit of metformin on weight loss [29].

Ovulation induction: Menstrual dysfunction has been found to correlate with the degree of insulin resistance and the insulin sensitizing agent metformin has been shown to restore menstrual cyclicity and increases the likelihood of ovulation [30]. The use of metformin as an ovulation induction agent has been called into question with large studies demonstrating no increased live birth rate when the agent was used alone and no additional benefit when added to clomiphene citrate [31-33]. In one clinical trial pre treatment with metformin for three months prior to starting clomiphene did significantly improve live birth rates [34]. Metformin may also enhance success of ovulation induction in women with body mass index $>35$ and those with demonstrated clomiphene resistance [33].

The effects of metformin before and during pregnancy are an area of considerable interest at this time. Some evidence suggests that its continued use during pregnancy may reduce early pregnancy loss and the risk of developing gestational diabetes [34-36].

In a direct head-to-head comparison letrozole, an aromatase inhibitor, has proven significantly more effective in achieving live birth than clomiphene especially in PCOS patients with obesity $[37,38]$.

Exogenous gonadotropins and laparoscopic ovarian drilling: Women resistant to ovulation induction with oral agents present a special problem. Ovulation induction with exogenous gonadotropins (injectable FSH and $\mathrm{LH}$ ) creates a significant risk for Ovarian Hyperstimulation Syndrome (OHSS) and multiple pregnancies. Proper counselling and careful monitoring during therapy are essential.

Laparoscopic ovarian drilling (a technique to destroy some of the androgen producing theca cells) is the modern day version of ovarian wedge resection [39]. Laser or diathermy of the interior (interstitial or theca cells) of the ovary will often result in an abrupt fall in circulating androgen levels [40] and resumption of ovulation with the possibility of spontaneous pregnancy. This technique avoids the risk of OHSS and multiple pregnancies associated with gonadotropin therapy but carries the risk of surgical complications and damage to the ovarian vascular supply leading to premature menopause [32].

If the goal is to avoid acne, hirsutism, irregular and heavy bleeding while avoiding pregnancy the goal is to shift to the "turned off" mode

Lifestyle modification: Once again lifestyle modification and weight loss will benefit any women with PCOS and obesity. A discussion of future cardiovascular risks of obesity, dyslipidemia etc., may be motivational.

Topical therapy: Eflornithine applied topically has shown to reduce mild hirsutism by inhibiting the enzyme ornithine decarboxylase in the pilosebaceous unit. By inhibiting cell growth it results in a diminished rate of facial hair growth [41].

\section{Systemic therapy}

Metformin: Insulin resistance is a common condition in PCOS and present in 14-24\% according to ESHRE/ ASRM criteria or $20-43 \%$ with NIH criteria [42]. Hyperinsulinemia augments ovarian androgen production [43,44]. A direct relationship exists between adiposity and surrogate measures of insulin resistance. Metformin has been shown to decrease ovarian androgen production but usually needs to be combined with an anti-androgen for optimal effect [45]. Metformin can delay the onset of diabetes by increasing insulin sensitivity $[46,47]$. Obese women with PCOS should be screened for impaired glucose tolerance with a $75 \mathrm{~g} 2$ hour glucose tolerance test at least every two years and similar screening should be conducted in thin women with PCOS beyond age 40 [48,49].

Combined hormonal contraceptives: Combined Hormonal Contraceptives (CHC) are more effective at menstrual cycle regulation than metformin and they have a synergistic effect on reducing androgen action (Figure 5). Estrogen in the combined contraceptive increases liver production of Sex Hormone Binding Globulin (SHBG) (thus reducing levels of free androgen) while the progestin component suppresses LH driven ovarian androgen production. CHCs provide contraception, eliminate watery cervical mucus, and are generally sufficient to prevent acne and oily skin. Pre-existing hair growth however requires additional management. Remember that combined hormonal contraceptives are contraindicated in women over age 35 who smoke cigarettes and that even in younger non-smokers obesity associated with PCOS may result in slightly greater risks for venous thromboembolism [50]. While oral contraceptives improve the phenotypic expression of PCOS they do not to alter the parameters associated with increased health risks [51].

Anti-androgens: The diuretic, spironolactone, is also a powerful inhibitor of androgen production and androgen receptor binding with beneficial effects on acne and hair growth. It has some progestational effects that can lead to excessive bleeding so it is often used in conjunction with a combined hormonal contraceptive [52]. Electrolyte monitoring in healthy women is not required [53]. The combined estrogen/ progestin contraceptive acts synergistically to reduce androgen action while avoiding menstrual dysfunction and providing contraception while on anti-androgen therapy. After 3 months on medication hair regrowth is often noticeably suppressed allowing for permanent elimination of remaining unwanted hair by laser or electrolysis treatments. Some women with PCOS and excessive androgen action will be aware of androgenetic alopecia. Unlike balding in men this hair loss occurs with preservation of the fronto-temporal hairline [54]. It is important to reassure women 
who are starting anti-androgen therapy that spironolactone decreases body hair but has the opposite effect on scalp hair loss.

Alternative anti-androgen medications include cyproterone acetate and flutamide both of which block the androgen receptor [33]. Finasteride which inhibits 5 a-reductase (type 2) needed for conversion of testosterone to dihydrotestosterone may be less effective for hirsutism because the 5 a-reductase enzyme in the pilosebaceous unit is primarily type 15 [41].

\section{Conclusion}

PCOS can be a confusing condition both for patients and Health Care Providers (HCP). However as more is learned about the condition and its contributory factors HCPs have an opportunity to provide logical explanations to their patients which in turn can enhance compliance with therapy and lead to successful reproductive outcomes.

For the majority of women presenting with irregular menses and evidence of gradual progression of hirsutism a diagnosis of PCOS is likely. The simple drawing presented here can be helpful to explain to affected women the link between obesity and reproductive dysfunction and can clarify treatment options, whether the goal is to restore fertility or to regulate menses and minimize androgen excess. Longer term metabolic consequences of PCOS are real and can be attenuated or delayed when the gynecological interventions include both weight loss and insulin sensitizers.

\section{References}

1. Randeva HS, Tan BK, Weickert MO, Lois K, Nestler JE, Sattar N, Lehnert $\mathrm{H}$, et al.Cardiometabolic aspects of the polycystic ovary syndrome. Endocrine Reviews 2012; 33(5): 812-841 doi: 10.1210/er.20121003.

2. Conway G; Dewailly D; Diamanti-Kandarakis E; Escobar-Morreale HF; Franks S; Gambineri A, et al. ESE PCOS Special Interest Group. The polycystic ovary syndrome: a position statement from the European Society of Endocrinology. European J Endocrinol 2014; 171(4):1-29 doi: 10.1530/EJE-14-0253

3. Dokras A. Cardiovascular disease risk in women with PCOS. Steroids 2013. 2013 Aug; 78(8): 773-6. doi: 10.1016/j.steroids.2013.04.009.

4. Dumesic DA, Lobo RA. Cancer risk and PCOS. Steroids 2013; 78(8): 782-5 doi: 10.1016/j.steroids.2013.04.004.

5. Vassilatou E. Nonalcoholic fatty liver disease and polycystic ovary syndrome. World J Gastroenterology 2014 14; 20(26):8351-63 doi: 10.3748/wjg.v20.i26.8351

6. Azziz R,Marin C, Hoq L, Badamgarav E, Song P. Health care-related economic burden of the polycystic ovary syndrome during the reproductive life span. J Clin Endocrinol Metab 2005; 90(8): 46504658

7. Zawadzki JK, Dunaif A. Diagnostic criteria for polycystic ovary syndrome: towards a rational approach. In: Dunaif A, Givens JR, Haseltine FP, Merriam GE (eds). Polycystic Ovary Syndrome. Current Issues in Endocrinology and Metabolism. Boston: Blackwell Scientific Publications; 1992: 377-384

8. Rotterdam ESHRE/ASRM-Sponsored PCOS Consensus Workshop Group 2004 Revised 2003 consensus on diagnostic criteria and long term health risks related to polycystic ovary syndrome. Hum Reprod 2004; 19:41-47

9. Balen AH, Laven JS, Tan SL, Dewailly D. Ultrasound assessment of the polycystic ovary: international consensus definitions. Hum Reprod Update. 2003; 9:505-14.

10. Broekmans FJ, Knauff EAH, Valkenburg O, Laven JS, Eijkemans MJ, Fauser BCJM. PCOS according to the Rotterdam consensus criteria: change in prevalence among WHO-II anovulationand association with metabolic factors. BJOG2006; 113: 1210-1217.

11.NIH Office of Disease Prevention. Final report of Evidence-based Methodology Workshop on Polycystic Ovary Syndrome (PCOS). 2012; 3-5

12. Dunaif A, Fauser BC. Renaming PCOS-a two-state solution. J ClinEndocrinol Metab. 2013; 98: 4325-4328. doi: 10.1210/jc.20132040.

13. Azziz R. Polycystic ovary syndrome: What's in a name? J Clin Endocrinol Metab, April 2014, 99(4): 1142-1145. doi: 10.1210/jc.2013-3996.

14. Azziz R, Sanchez LA, Knochenhauer ES, Moran C, Lazenby J,Stephens $\mathrm{KC}$, et al. Androgen excess in women: Experience with over 1000 consecutive patients. J Clin Endocrinol Metab 2004; 89(2): 453-462

15. Reid RL, Van Vugt DA. Weight-related changes in reproductive function. Fertil Steril 1987; 48(6): 905-913

16. Napheys GH. The physical life of woman: advice to the maiden, wife and mother. Philadelphia, George MacLean 1874 p 87.

17. Luke B, Brown MB, Stern JE, Missmer SA, Fujimoto VY, Leach R, for the SART writing group. Female obesity adversely affects assisted reproductive technology (ART) pregnancy and live birth rates. Human Reproduction 2010; 26(1):245-252 doi: 10.1093/humrep/deq306

18. Bates GW, Whitworth NS. Effect of body weight loss on plasma androgens in obese infertile women. Fertil Steril 1982; 38: 406

19. Pasquali R, Antenucci D, Casimirri F, Venturoli S, Paradisi R, Fabbri $\mathrm{R}$, Balestra V, et al. Clinical and hormonal characteristics of obese amenorrheichyperandrogenic women before and after weight loss. J Clin Endocrinol Metab 1989; 68(1):173

20. Harlass FE,Plymate SR; Fariss BL; Belts RP.Weight loss is associated with correction of gonadotropin and sex steroid abnormalities in the obese anovulatory female. Fertil Steril 1984; 42: 649

21. Nybacka A , Carlstrom K, Stahle A, et al. Randomized comparison of the influence of dietary management and/or physical exercise on ovarian function and metabolic parameters in overweight women with polycystic ovary syndrome.Fertil Steril 2011; 96: 1508-1513 doi: 10.1016/j.fertnstert.2011.09.006.

22. Harrison CL, Lombard CB, Moran LJ, Teede HJ. Exercise therapy in polycystic ovary syndrome: a systematic review. Hum Reprod Update. 2011; 17: 171-183. doi: 10.1093/humupd/dmq045

23.Escobar-Morreale HF, Botella-Carretero JI, Alvarez-Blasco F, et al. The polycystic ovary syndrome associated with morbid obesity may resolve after weight loss induced by bariatric surgery. J Clin Endocrinol Metab 2005; 90: 6364-6369.

24. Bhagavath B, Vitek W, Queenan J, Hoeger K. Metformin and other insulin sensitizers in polycystic ovary syndrome. Semin Reprod Med 2014; 32: 323-330 doi: 10.1055/s-0034-1375186.

25. Hurd WW, Abdel-Rahman MY, Ismail SA, et al. Comparison of diabetes mellitus and insulin resistance screening methods for women with polycysticovary syndrome. Fertil Steril 2011; 96:1043-7. doi: 


\subsection{6/j.fertnstert.2011.07.002}

26. Azziz R. We should avoid indiscriminate use of insulin sensitizers in women with polycystic ovary syndrome. Fertil Steril 2003; 80(2): 264-5

27. Nestler J, Stovall D, Akhter N, Iuorno MJ, Jakubowicz DJ. Strategies for the use of insulin sensitizing drugs to treatinfertility in women with polycystic ovary syndrome. Fertil Steril 2002; 77(2): 209-15

28. Dunaif A. Hyperandrogenemia is necessary but not sufficient forpolycystic ovary syndrome. Fertil Steril 2003; 80(2): 262-3

29. Domecq JP, Prutsky G, Leppin A et al. Drugs Commonly Associated With Weight Change:A Systematic Review and Meta-analysis.J Clin Endocrinol Metab 2015;100: 363-70. doi: 10.1210/jc.2014-3421.

30. Tang T, Lord JM, Norman RJ, Yasmin E, Balen AH. Insulin-sensitising drugs (metformin, rosiglitazone, pioglitazone, D-chiro-inositol) for women with polycystic ovary syndrome, oligo-amenorrhoea and subfertility.Cochrane Database of Systematic Reviews. 2012 May 16; 5: CD003053. doi: 10.1002/14651858.CD003053.pub5.

31. Legro RS Barnhart HX, Schlaff WD, et al. Cooperative Multicenter Reproductive Medicine Network. Clomiphene, metformin,or both for infertility in the polycystic ovary syndrome. N Engl J Med. 2007; 356: $551-66$.

32. Perales-Puchalt A, Legro RS. Ovulation induction in women with polycystic ovary syndrome. Steroids 2013, 78: 767-72. doi: 10.1016/j. steroids.2013.05.005.

33. Legro RS; Arslanian SA; Ehrmann DA; Hoeger KM; Murad MH; Pasqual $\mathrm{R}$; Welt CK; Diagnosis and treatment of polycystic ovary syndrome: an Endocrine Society clinical practice guideline. J Clin Endocrinol Metab 2013; 98(12): 4565-92. doi: 10.1210/jc.2013-2350

34. Morin-Papunen L, Rantala AS, Unkila-Kallio L, et al. Metformin improves pregnancy and live-birth rates in women with polycystic ovary syndrome (PCOS): a multicenter, double-blind, placebocontrolled randomized trial. J Clin Endocrinol Metab 2012; 97(5): 1492-500. doi: 10.1210/jc.2011-3061

35. Ghazeeri GS, Nassar AH, Younes Z, et al. Pregnancy outcomes and the effect of metformin treatment in women with polycystic ovary syndrome: an overview. Acta Obstet GynecolScand 2012; 91(6): 65878. doi: 10.1111/j.1600-0412.2012.01385.x

36. De Leo V, Musacchio MC, Piomboni P, et al. The administration of metformin during pregnancy reduces polycystic ovary syndrome related gestational complications. Eur J Obstet GynecolReprodBiol 2011; 157: 63-66. doi: 10.1016/j.ejogrb.2011.03.024

37. NIH/NICHD Reproductive Medicine Network. Effect of letrozole versus clomiphene on live birth in women with anovulatory infertility due to polycystic ovary syndrome (PCOS): a randomized double- blind multicenter trial. Fertil Steril. 2013; 100(3 suppl): S51.

38. Legro RS, Brzyski RG, Diamond MP, et al. Letrozole versus clomiphene for infertility in the polycystic ovary syndrome. NEJM 2014; 371 (2): 119-29. doi: 10.1056/NEJMoa1313517

39. Farquhar C, Vandekerckhove P, Lilford R. Laparoscopic "drilling" by diathermy or laser for ovulation induction in anovulatory polycystic ovary syndrome. Cochrane Database Syst Rev 2005; (3): CD001122. doi: 10.1002/14651858.CD001122.pub4.

40. Greenblatt E; Casper RF. Endocrine changes after laparoscopic ovarian cautery in polycystic ovarian syndrome.Amer J Obstet Gynecol. 1987; 156(2): 279-85

41. Ehrmann DA. Polycystic ovary syndrome. N Engl J Med 2005; 352
1223-36

42.Lim SS, Norman R, Davies MJ, Moran LJ. The effect of obesity on polycystic ovary syndrome:a systematic review and metaanalysis. Obesity Reviews 2013; 14: 95-10. doi: 10.1111/j.1467789X.2012.01053.x.

43. Nelson VL, Qin KN, Rosenfield RL, et al. The biochemical basis for increased testosterone production in theca cells propagatedfrom patients with polycystic ovary syndrome. J Clin Endocrinol Metab 2001; 86: 5925-33.

44.Tosi F, Negri C, Perrone F, et al. Hyperinsulinemia amplifies GnRH agoniststimulated ovarian steroid secretion in women with polycystic ovary syndrome.J Clin Endocrinol Metab 2012; 97: 1712-1719. doi: 10.1210/jc.2011-2939.

45. Ganie MA, Khurana ML, Nisar S, Shah PA, Shah ZA, KulshresthaB, et al. Improved efficacy of low-dose spironolactone and metformin combination than either drug alone in the management of women with polycystic ovary syndrome (PCOS): a six-month, open-label randomized study. J Clin Endocrinol Metab 2013; 98(9): 3599-3607. doi: $10.1210 /$ jc.2013-1040

46. Cheang, K. I. Long-term effect of metformin on metabolic parameters in the polycystic ovary syndrome. Diabetes \& vascular disease research 2009; 6(2): 110-119. doi: 10.1177/1479164109336050.

47. Palomba S,Falbo A,Zullo F,Orio F Jr. Evidence-based and potential benefits of metformin in the polycystic ovary syndrome: a comprehensivereview. Endocr. Rev 2009; 30: 1-50. doi: 10.1210/ er.2008-0030.

48. Huanga G, Coviello A. Clinical update on screening, diagnosis and management of metabolic disorders and cardiovascular risk factors associated with polycystic ovary syndrome. Curr Opin Endocrinol Diabetes Obes 2012, 19:512-519. doi: 10.1097/ MED.0b013e32835a000e.

49. Salley KES, Wickham EP, Cheang KI, Essah PA, Karjane NW, Nestler JE. Glucose intolerance in polycystic ovary syndrome: a position statement of the AndrogenExcess Society. J Clin Endocrinol Metab. 2007; 92: 4546-56

50. Seaman HE de Vries CS; Farmer RD. The risk of venous thromboembolism in women prescribed cyproterone acetate in combination with ethinyl estradiol: a nested cohort analysis and casecontrol study. Pharmaco epidemiology and Drug Safety 2004; 13: 427 36

51. Mes-Krowinkel MG; Louwers YV; Mulders AG; de Jong FH; Fauser BC; Laven JS. Influence of oral contraceptives on anthropomorphometric, endocrine, and metabolic profiles of anovulatory polycystic ovary syndrome patients. Fertil Steril 2014; 101(6): 1757-65. doi: 10.1016/j.fertnstert.2014.02.039

52. Escobar-Morreale HF, Carmina E, Dewailly D, Gambineri A, Kelestimur F, Moghetti P, et al. Epidemiology, diagnosis and management of hirsutism: a consensus statement by the Androgen Excess and Polycystic Ovary Syndrome Society. Human Reproduction Update 2012:18 146-170. doi: 10.1093/humupd/dmr042.

53. Plovanich $\mathrm{M}$ et al. Low usefulness of potassium monitoring among healthy young women taking spironolactone for acne. JAMA Dermatology 2015; 151(9):941-4. doi: 10.1001/ jamadermatol.2015.34.

54. Reid RL, Van Vugt DA. Hair loss in women. Obstet Gynecol Survey 1988; 43(3): 135-41. 